Keywords: rucaparib; carboplatin; PARP inhibitor; pharmacokinetics and pharmacodynamics; breast cancer; ovarian cancer; pancreatic cancer; BRCA1, BRCA2

\title{
A phase I study of intravenous and oral rucaparib in combination with chemotherapy in patients with advanced solid tumours
}

Richard H Wilson ${ }^{1,2}$, TR Jeffry Evans ${ }^{3}$, Mark R Middleton ${ }^{4}$, L Rhoda Molife ${ }^{5}$, James Spicer ${ }^{6}$, Veronique Dieras ${ }^{7}$, Patricia Roxburgh ${ }^{3}$, Heidi Giordano ${ }^{8}$, Sarah Jaw-Tsai ${ }^{8}$, Sandra Goble ${ }^{8}$ and Ruth Plummer ${ }^{\star}, 9,10$

${ }^{1}$ Centre for Cancer Research and Cell Biology, Queen's University Belfast, 97 Lisburn Road, Belfast BT9 7AE, UK; ${ }^{2}$ Northern Ireland Cancer Center, Belfast City Hospital, 51 Lisburn Road, Belfast BT9 7AB, UK; ${ }^{3}$ Beatson West of Scotland Cancer Centre, and Institute of Cancer Sciences, University of Glasgow, Garscube Estate, Switchback Road, Bearsden, Glasgow G61 1BD, UK; ${ }^{4}$ National Institute for Health Research Biomedical Research Centre, Churchill Hospital, and Department of Oncology, University of Oxford, Old Road Campus Research Building, Roosevelt Drive, Oxford OX3 7DQ, UK; ${ }^{5}$ Drug Development Unit, Royal Marsden Hospital/Institute of Cancer Research, Downs Road, Sutton, Surrey SM2 5PT, UK; ${ }^{6}$ Division of Cancer Studies, King's College London, Guy's Hospital, Great Maze Pond, London SE1 9RT, UK; ${ }^{7}$ Department of Medical Oncology, Institut Curie, 26, rue d'Ulm, Paris 75005 France; ${ }^{8}$ Clovis Oncology, Inc., Boulder, 5500 Flatiron Parkway, Boulder, CO 80301, USA; ${ }^{9}$ Northern Centre for Cancer Care, Freeman Hospital, Freeman Road, High Heaton, Newcastle Upon Tyne NE7 7DN, UK and ${ }^{10}$ Northern Institute for Cancer Research, Newcastle University, Paul O'Gorman Building, Framlington Place, Newcastle Upon Tyne NE2 4HH, UK

Background: This study evaluated safety, pharmacokinetics, and clinical activity of intravenous and oral rucaparib, a poly(ADPribose) polymerase inhibitor, combined with chemotherapy in patients with advanced solid tumours.

Methods: Initially, patients received escalating doses of intravenous rucaparib combined with carboplatin, carboplatin/paclitaxel, cisplatin/ pemetrexed, or epirubicin/cyclophosphamide. Subsequently, the study was amended to focus on oral rucaparib (once daily, days 1-14) combined with carboplatin (day 1) in 21-day cycles. Dose-limiting toxicities (DLTs) were assessed in cycle 1 and safety in all cycles.

Results: Eighty-five patients were enrolled (22 breast, 15 ovarian/peritoneal, and 48 other primary cancers), with a median of three prior therapies (range, 1-7). Neutropenia (27.1\%) and thrombocytopenia (18.8\%) were the most common grade $\geqslant 3$ toxicities across combinations and were DLTs with the oral rucaparib/carboplatin combination. Maximum tolerated dose for the combination was $240 \mathrm{mg}$ per day oral rucaparib and carboplatin area under the curve $5 \mathrm{mg} \mathrm{ml}^{-1} \mathrm{~min}^{-1}$. Oral rucaparib demonstrated dose-proportional kinetics, a long half-life $(\approx 17 \mathrm{~h})$, and good bioavailability (36\%). Pharmacokinetics were unchanged by carboplatin coadministration. The rucaparib/carboplatin combination had radiologic antitumour activity, primarily in BRCA1- or BRCA2-mutated breast and ovarian/peritoneal cancers.

Conclusions: Oral rucaparib can be safely combined with a clinically relevant dose of carboplatin in patients with advanced solid tumours (Trial registration ID: NCT01009190).

The poly (ADP-ribose) polymerase (PARP) family includes enzymes that are involved in the repair of single-strand breaks, a common type of DNA damage, thus preventing the formation of
DNA double-strand breaks (Schreiber et al, 2006). The DNA double-strand breaks can be repaired by a separate process known as homologous recombination, mediated by BRCA1 and BRCA2

*Correspondence: Dr R Plummer; E-mail: Ruth.Plummer@newcastle.ac.uk 
(Moynahan et al, 1999, 2001; Venkitaraman, 2002). Tumours harbouring a BRCA mutation or other defect in homologous recombination repair are sensitive to PARP inhibitors, because cells accumulate unrepaired single-strand breaks that are converted to double-strand breaks that cannot be repaired and therefore result in cell death (Bryant et al, 2005; Farmer et al, 2005; Helleday et al, 2007, 2008; Ashworth, 2008). Furthermore, studies have demonstrated that PARP inhibition can interfere with the alternative nonhomologous end-joining DNA repair pathway that is upregulated in homologous recombination-deficient cells (Helleday, 2011; Ceccaldi et al, 2015; Konstantinopoulos et al, 2015; Mateos-Gomez et al, 2015). The PARP inhibitors can also result in trapping of PARP-1 and PARP-2 at the site of the DNA break, resulting in obstructed replication forks that require functional homologous recombination for repair (Helleday, 2011; Murai et al, 2012; O'Connor, 2015).

Consistent with the role of PARPs in DNA repair, inhibiting PARP has been shown to increase the potency of DNA-damaging agents, such as chemotherapy and radiotherapy (Calabrese et al, 2004; Donawho et al, 2007; Thomas et al, 2007; Ihnen et al, 2013). Preclinical data suggest that a PARP inhibitor in combination with carboplatin or cisplatin has enhanced efficacy over either agent individually in BRCA-mutated tumours (Evers et al, 2008; Drew et al, 2011; Clark et al, 2012). The synergistic effect of these combinations may be the result of an increase in DNA damage (e.g., intrastrand crosslinks) induced by platinum-based chemotherapies that requires repair through PARP-dependent pathways.

Rucaparib (formerly known as AG-014699 and PF-01367338) is a potent small-molecule inhibitor of PARP-1, PARP-2, and PARP3 that is being developed for the treatment of ovarian cancer and other tumour types associated with homologous recombination deficiency (HRD), including BRCA1 and BRCA2 mutations (Thomas et al, 2007; Drew et al, 2011; Swisher et al, 2017). In a phase II study in patients with advanced ovarian or breast cancer associated with a germline BRCA1/2 mutation, continuous dosing of single-agent oral rucaparib led to a higher rate of response than intermittent intravenous (i.v.) dosing (response rate, $18 \%$ vs 2\%) (Drew et al, 2016). A subsequent phase I-II dose-escalation study established the recommended phase II dose of single-agent oral rucaparib as $600 \mathrm{mg}$ twice daily (Kristeleit et al, 2014) and demonstrated the clinical activity and manageable safety profile of rucaparib in patients with advanced solid tumours, including $B R C A$-mutated ovarian and breast cancers (Kristeleit et al, 2014;
Shapira-Frommer et al, 2015). In phase I and II studies, the combination of i.v. rucaparib and the DNA-alkylating agent temozolomide was active in patients with advanced solid tumours and resulted in increased activity compared with historical data of single-agent temozolomide in patients with metastatic melanoma (Plummer et al, 2008, 2013).

This phase I dose-escalation study evaluated rucaparib in combination with several standard chemotherapeutic regimens in patients with advanced solid tumours, independent of BRCA status. The study initially explored an i.v. formulation of rucaparib; however, during the conduct of this study, an oral formulation of rucaparib was developed that could be administered for a longer duration, and the study was amended to evaluate the oral bioavailability of this new formulation. Once bioavailability was established, the study was amended to evaluate oral rucaparib in combination with carboplatin. Here, we report final results from all patients enrolled in the study, with a focus on those who received oral rucaparib in combination with carboplatin.

\section{MATERIALS AND METHODS}

Study design. This study was an open-label, multicentre, doseescalating phase I study of rucaparib administered in combination with one of four different standard chemotherapeutic regimens (NCT01009190). Eligible patients $\geqslant 18$ years of age had a histologically or cytologically confirmed advanced solid tumour, an Eastern Cooperative Oncology Group (ECOG) Performance Status of 0 or 1 , life expectancy of $\geqslant 12$ weeks, and adequate bone marrow, liver, and renal function. All BRCA testing was done locally and was not verified by the sponsor. The primary objective was to assess safety and tolerability and estimate the maximum tolerated dose (MTD) and/or select the recommended phase II dose of rucaparib in combination with chemotherapy. Secondary objectives were to characterise the pharmacokinetics (PK) and assess the antitumour activity of rucaparib when combined with chemotherapy.

The study was approved by the Research Ethics Committee for all participating institutions and conducted in accordance with the Declaration of Helsinki and the Good Clinical Practice Guidelines of the International Conference on Harmonisation. Patients gave written informed consent before undergoing any study-related procedures.

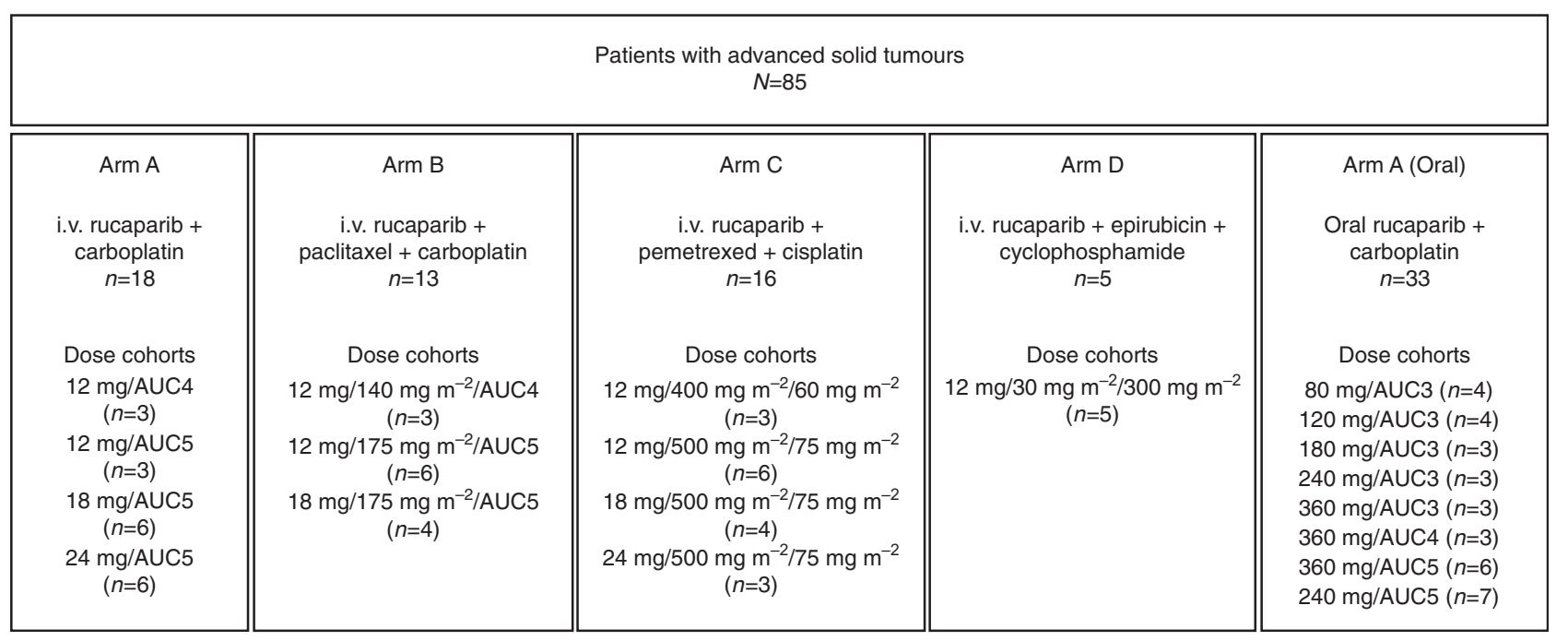

Figure 1. Study treatment arms. 
Treatments. Patients received escalating doses of i.v. rucaparib (days 1-3) with standard doses of chemotherapeutic regimens. Initial starting doses for each chemotherapy were as follows: arm A, rucaparib $(24 \mathrm{mg})+$ carboplatin (area under the curve

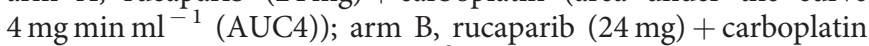
(AUC4) + paclitaxel $\left(140 \mathrm{mg} \mathrm{m}^{-2}\right)$; arm C, rucaparib $(24 \mathrm{mg})+$ cisplatin $\left(60 \mathrm{mg} \mathrm{m}^{-2}\right)+$ pemetrexed $\left(400 \mathrm{mg} \mathrm{m}^{-2}\right)$; and arm $\mathrm{D}$, rucaparib $(12 \mathrm{mg})+$ epirubicin $\left(30 \mathrm{mg} \mathrm{m}^{-2}\right)+$ cyclophosphamide $\left(300 \mathrm{mg} \mathrm{m}^{-2}\right)$ (Figure 1). Initially, patients received chemotherapy (day 1) and i.v. rucaparib (days 1-3) in 21-day treatment cycles. However, during the conduct of the study, an oral formulation of rucaparib was developed and introduced under a protocol amendment, with an additional secondary objective to determine its absolute oral bioavailability. Subsequently, the i.v. rucaparib arms were discontinued and three of the chemotherapy arms (B, C, and D) were closed to further enrolment. Thereafter, all enrolled patients received oral rucaparib in combination with i.v. carboplatin (arm A, oral rucaparib) (Figure 1).

Treatment with rucaparib in combination with chemotherapy was continued until progression, unacceptable toxicity, patient's withdrawal of consent, or as deemed appropriate by the judgement of the treating physician (whichever came first).

Oral rucaparib in combination with carboplatin. Patients received lead-in doses of i.v. and oral rucaparib on days -10 and -5 , respectively, followed by carboplatin (AUC3, 4 , or 5) on day 1 and oral rucaparib on days 1-14 of every 21-day treatment cycle. The i.v. lead-in dose of rucaparib was discontinued once sufficient bioavailability data for oral rucaparib were available. The starting dose of $80 \mathrm{mg}$ oral rucaparib was based on the safety established with up to $24 \mathrm{mg} \mathrm{m}^{-2}$ i.v. rucaparib in combination with chemotherapy and an oral bioavailability of $36 \%$. The protocol prespecified dose cohorts of 80,120 , and $180 \mathrm{mg}$ oral rucaparib, after which rucaparib was to be escalated in $50 \%$ increments. Additional doses of 240 and $360 \mathrm{mg}$ were subsequently evaluated. Similarly, carboplatin dosing began at AUC3, with a plan to escalate to AUC5 once the MTD of rucaparib was established; however, escalation was modified to evaluate AUC4 carboplatin before escalating to AUC5. Patients discontinuing carboplatin could continue to receive oral rucaparib.

Safety and efficacy assessments. Safety assessments included collection of adverse events (AEs) and serious AEs (defined by National Cancer Institute Common Terminology Criteria for Adverse Events version 3.0; Pedersen et al, 2013), as well as vital signs, physical examination, 12-lead electrocardiogram, laboratory assessments, and verification of concurrent medications. Safety variables and demographic data were presented descriptively. The safety analysis set included all enrolled patients who started treatment.

Dose-limiting toxicities (DLTs) were defined as any of the following occurring during cycle 1: grade 4 neutropenia lasting $\geqslant 7$ days; febrile neutropenia; grade 3 thrombocytopenia lasting $\geqslant 7$ days with bleeding or grade 4 thrombocytopenia lasting $>3$ days; grade $\geqslant 3$ toxicity despite the use of adequate/maximal medical interventions and/or prophylaxis as dictated by local institutional clinical practices or the judgement of the investigator; grade 2 neurotoxicity that did not recover to grade $\leqslant 1$ within 2 weeks of planned dose; toxicities that resulted in a delay of $>14$ days in initiation of cycle 2 dosing; or toxicities that resulted in failure to deliver $\geqslant 80 \%$ of the assigned oral rucaparib doses.

Initially, at least three patients were treated at each dose level. If no DLT was observed, the dose was escalated for the next cohort of three patients. If a DLT was observed in one of the three patients, three additional patients were enrolled and treated at the same dose level. If no further DLT was observed, the next dose level was opened. Dose escalation continued until DLTs were observed in at least two of the three to six patients treated at that dose level; this dose was then considered above the MTD and further dose escalations were stopped. When a dose was concluded to be above the MTD, the preceding lower dose was declared the MTD, but only if six patients had already been treated at this lower dose. Otherwise, three additional patients were treated at this lower dose, and if none or one of those patients had a DLT, this lower dose was declared the MTD.

All patients who received at least one dose of study medication were evaluable for toxicity. Patients were considered nonevaluable for DLT assessments if they missed the rucaparib lead-in doses, had administration of $<80 \%$ of the planned cycle 1 doses of rucaparib, and/or had administration of $<80 \%$ of the planned cycle 1 doses of chemotherapy for that dose level (provided that the reduction did not result from toxicity).

Antitumour activity was assessed by the investigators according to Response Evaluation Criteria in Solid Tumor version 1.1 (RECIST) (Eisenhauer et al, 2009) through radiological tumour assessments performed every two cycles and/or at the end of treatment, whichever occurred first.

Pharmacokinetics. On cycle 1 days $-10,-5,1$, and 14, plasma samples were obtained from all patients before rucaparib dosing and at 15 and $30 \mathrm{~min}$, and at $1,1.5,2.5,4,6,10$, and $24 \mathrm{~h}$ after the start of the rucaparib administration (i.v. infusion (day -10) or oral (days $-5,1$, and 14)). On cycle 1 days -10 and -5 , samples were also obtained $48 \mathrm{~h}$ after the start of rucaparib administration. Rucaparib concentration was determined using liquid chromatography with tandem mass spectrometry. The PK assay was validated by York Bioanalytical Solutions (York, UK) in accordance with the US Food and Drug Administration's Bioanalytical Method Validation Guidance for Industry and Crystal City III Conference (US Food and Drug Administration, 2001; Viswanathan et al, 2007; Fast et al, 2009). The PK concentration analysis population was defined as all treated patients who had at least one concentration measurement in at least one treatment period (cycle 1). The PK parameter analysis population was defined as all treated patients who had at least one of the PK parameters of interest in at least one treatment period (cycle 1).

Standard plasma PK parameters for rucaparib were estimated using noncompartmental methods and included: maximum plasma drug concentration $\left(\mathrm{C}_{\max }\right)$; area under the plasma concentration time curve from time 0 to the last sampling time with measurable values $\left(\mathrm{AUC}_{0-t}\right)$ and from time 0 to $24 \mathrm{~h}\left(\mathrm{AUC}_{0-24}\right)$; and half-life $\left(t_{1 / 2}\right)$. Plasma clearance or apparent plasma clearance and steady-state volume of distribution were calculated for rucaparib. The oral bioavailability of rucaparib was calculated as the ratio of dose-normalised $\mathrm{AUC}_{0-t}$ or $\mathrm{AUC}_{\text {inf }}$ (data permitting) determined using oral rucaparib PK data collected on cycle 1 day -5 to that determined using the i.v. PK data collected on cycle 1 day -10 . Pharmacokinetic parameters were summarised with the geometric mean and the coefficient of variation $(\mathrm{CV})$. The ratio of $\mathrm{C}_{\max }$ and $\mathrm{AUC}_{0-24}$ of rucaparib administered in combination with chemotherapies to those of rucaparib alone was calculated and summarised, with mean and $\mathrm{CV} \%$ to evaluate the effect of chemotherapies on the PK of rucaparib for both the i.v. dose (day -10$)$ and oral dose (day - 5). Additional PK parameters examined and analyses performed are described in the Supplementary Methods.

\section{RESULTS}

Patients and treatments. Eighty-five patients were enrolled at seven sites in the United Kingdom and France (Table 1). Median age was 55 years (range, 20-76 years), approximately two-thirds of patients were female, and all had an ECOG Performance Status of 
Table 1. Patient demographics and disease characteristics

\begin{tabular}{|c|c|c|c|c|c|c|}
\hline Variable & $\begin{array}{l}\text { Arm A, i.v. } \\
\text { rucaparib }+ \\
\text { carboplatin } \\
\quad(n=18)\end{array}$ & $\begin{array}{l}\text { Arm B, i.v. } \\
\text { rucaparib }+ \\
\text { carboplatin/ } \\
\text { paclitaxel } \\
(n=13)\end{array}$ & $\begin{array}{l}\text { Arm C, i.v. } \\
\text { rucaparib }+ \\
\text { cisplatin/ } \\
\text { pemetrexed } \\
\quad(n=16)\end{array}$ & $\begin{array}{l}\text { Arm D, i.v. } \\
\text { rucaparib + } \\
\text { epirubicin/ } \\
\text { cyclophosphamide } \\
(n=5)\end{array}$ & $\begin{array}{l}\text { Arm A, } \\
\text { oral rucaparib + } \\
\text { carboplatin } \\
(n=33)\end{array}$ & $\begin{array}{l}\text { All patients } \\
\qquad(N=85)\end{array}$ \\
\hline Median age (range), years & $51.5(23-68)$ & $61.0(39-69)$ & $50.5(32-68)$ & $41.0(32-53)$ & $61.0(20-76)$ & $55.0(20-76)$ \\
\hline $\begin{array}{l}\text { Gender, n (\%) } \\
\text { Female } \\
\text { Male }\end{array}$ & $\begin{array}{l}11(61.1) \\
7(38.9)\end{array}$ & $\begin{array}{l}7(53.8) \\
6(46.2)\end{array}$ & $\begin{array}{l}10(62.5) \\
6(37.5)\end{array}$ & $\begin{array}{l}4(80.0) \\
1(20.0)\end{array}$ & $\begin{array}{l}23(69.7) \\
10(30.3)\end{array}$ & $\begin{array}{l}55(64.7) \\
30(35.3)\end{array}$ \\
\hline $\begin{array}{l}\text { Race, n (\%) } \\
\text { Asian } \\
\text { Black } \\
\text { White }\end{array}$ & $\begin{array}{c}0 \\
1(5.6) \\
17(94.4)\end{array}$ & $\begin{array}{c}0 \\
1(7.7) \\
12(92.3)\end{array}$ & $\begin{array}{c}1(6.3) \\
0 \\
15(93.8)\end{array}$ & $\begin{array}{c}0 \\
0 \\
5(100.0)\end{array}$ & $\begin{array}{c}0 \\
0 \\
33(100.0)\end{array}$ & $\begin{array}{c}1(1.2) \\
2(2.4) \\
82(96.5)\end{array}$ \\
\hline $\begin{array}{l}\text { ECOG PS, n (\%) } \\
0 \\
1\end{array}$ & $\begin{array}{c}7(38.9) \\
11(61.1)\end{array}$ & $\begin{array}{l}6(46.2) \\
7(53.8)\end{array}$ & $\begin{array}{c}6(37.5) \\
10(62.5)\end{array}$ & $\begin{array}{c}5(100.0) \\
0\end{array}$ & $\begin{array}{l}16(48.5) \\
17(51.5)\end{array}$ & $\begin{array}{l}40(47.1) \\
45(52.9)\end{array}$ \\
\hline $\begin{array}{l}\text { Primary cancer diagnosis, } n(\%) \\
\text { Breast } \\
\text { Ovarian/peritoneal } \\
\text { Lung } \\
\text { Pancreas } \\
\text { Rectal } \\
\text { Unknown primary } \\
\text { Other }{ }^{\text {a }}\end{array}$ & $\begin{array}{c}7(38.9) \\
2(11.1) \\
1(5.6) \\
0 \\
3(16.7) \\
1(5.6) \\
4(22.2)\end{array}$ & $\begin{array}{c}1(7.7) \\
1(7.7) \\
2(15.4) \\
0 \\
0 \\
0 \\
9(69.2)\end{array}$ & $\begin{array}{c}4(25.0) \\
2(12.5) \\
1(6.3) \\
2(12.5) \\
0 \\
0 \\
7(43.8)\end{array}$ & $\begin{array}{c}4(80.0) \\
0 \\
1(20.0) \\
0 \\
0 \\
0 \\
0\end{array}$ & $\begin{array}{c}6(18.2) \\
10(30.3) \\
3(9.1) \\
2(6.1) \\
1(3.0) \\
0 \\
11(33.3)\end{array}$ & $\begin{array}{c}22(25.9) \\
15(17.6) \\
8(9.4) \\
4(4.7) \\
4(4.7) \\
1(1.2) \\
31(36.5)\end{array}$ \\
\hline $\begin{array}{l}\text { BRCA1 test results, } n(\%) \\
\text { Positive } \\
\text { Negative } \\
\text { Unknown } \\
\text { Not tested }\end{array}$ & $\begin{array}{c}2(11.1) \\
3(16.7) \\
0 \\
13(72.2)\end{array}$ & $\begin{array}{c}1(7.7) \\
0 \\
0 \\
12(92.3)\end{array}$ & $\begin{array}{c}2(12.5) \\
0 \\
0 \\
14(87.5)\end{array}$ & $\begin{array}{c}0 \\
3(60.0) \\
0 \\
2(40.0)\end{array}$ & $\begin{array}{c}2(6.1) \\
3(9.1) \\
2(6.1) \\
26(78.8)\end{array}$ & $\begin{array}{c}7(8.2) \\
9(10.6) \\
2(2.4) \\
67(78.8)\end{array}$ \\
\hline $\begin{array}{l}\text { BRCA2 test results, } n(\%) \\
\text { Positive } \\
\text { Negative } \\
\text { Unknown } \\
\text { Not tested }\end{array}$ & $\begin{array}{c}2(11.1) \\
1(5.6) \\
1(5.6) \\
14(77.8)\end{array}$ & $\begin{array}{c}0 \\
1(7.7) \\
0 \\
12(92.3)\end{array}$ & $\begin{array}{c}0 \\
2(12.5) \\
0 \\
14(87.5)\end{array}$ & $\begin{array}{c}0 \\
3(60.0) \\
0 \\
2(40.0)\end{array}$ & $\begin{array}{c}1(3.0) \\
4(12.1) \\
1(3.0) \\
27(81.8)\end{array}$ & $\begin{aligned} & (3.5) \\
11 & (12.9) \\
& 2(2.4) \\
69 & (81.2)\end{aligned}$ \\
\hline $\begin{array}{l}\text { Median no. of prior anticancer } \\
\text { therapies ( } \mathrm{min}, \mathrm{max} \text { ) }\end{array}$ & $2.5(1,5)$ & $2.0(1,6)$ & $2.0(1,6)$ & $3.0(2,5)$ & $3.0(1,7)$ & $3.0(1,7)$ \\
\hline \multicolumn{7}{|c|}{$\begin{array}{l}\text { Abbreviations: ECOG PS = Eastern Cooperative Oncology Group Performance Status; i.v. }=\text { intravenous. } \\
\text { a Primary cancer diagnosis sites, including: appendix }(n=2) \text {, colon }(n=2) \text {, endometrium }(n=2) \text {, pleura }(n=2) \text {, stomach }(n=2) \text {, abdomen }(n=1) \text {, adrenal glands }(n=1) \text {, back }(n=1) \text {, bladder } \\
(n=1) \text {, oesophagus }(n=1) \text {, ear }(n=1) \text {, face }(n=1) \text {, forearm }(n=1) \text {, gastroesophageal junction }(n=1) \text {, left leg }(n=1) \text {, liver }(n=2) \text {, prostate }(n=1) \text {, shoulder }(n=1) \text {, skin }(n=1) \text {, testes }(n=1) \text {, and } \\
\text { not available }(n=5) \text {. }\end{array}$} \\
\hline
\end{tabular}

0 or 1 . Of the 85 patients, $22(25.9 \%)$ had breast cancer, $15(17.6 \%)$ had ovarian/peritoneal cancer, 8 (9.4\%) had lung cancer, 4 (4.7\%) each had pancreatic or rectal cancer, 31 (36.5\%) had other primary cancers, and $1(1.2 \%)$ patient had a carcinoma of unknown primary origin. The $B R C A$ test results were unavailable for most patients $(78.8 \%$ and $81.2 \%$ of patients did not undergo BRCA1 or $B R C A 2$ testing, respectively). The median number of prior anticancer therapies was three (range, 1-7).

All patients had discontinued the study as of 2 April 2014. The median number of cycles initiated was 5 (range, 1-7) in arm A (i.v. rucaparib; $n=18$ ), 4 (range, $1-31$ ) in arm A (oral rucaparib; $n=33$ ), 4 (range, $1-6)$ in arm B $(n=13), 4$ (range, $1-7)$ in arm C $(n=16)$, and 1 (range, $1-4)$ in arm D $(n=5)$. Eight of $18(44.4 \%)$ patients from arm A (i.v. rucaparib) and 17 of 33 (51.5\%) patients from arm A (oral rucaparib) had one or more delays ( $\geqslant 1$ week) between treatment cycles. These occurred between cycles 1 and 2 in 1 (5.6\%) patient in arm A (i.v. rucaparib) and $9(27.3 \%)$ patients in arm A (oral rucaparib). Four of 18 (22.2\%) patients from arm A (i.v. rucaparib) had a dose reduction of carboplatin; 8 of 33 (24.2\%) patients from arm A (oral rucaparib) had a dose reduction, including 6 (21.2\%) of carboplatin, 1 (3.0\%) of rucaparib, and 1 (3.0\%) of both drugs. Across all cohorts, $76(89.4 \%)$ discontinued treatment with the following as the primary reason: objective progression or relapse (42 patients, $55.3 \%), \mathrm{AE}$ (14 patients, $18.4 \%)$, global deterioration of health status (8 patients, $10.5 \%$ ), no longer willing to participate in the study (5 patients, 6.6\%), and other (7 patients, 9.2\%). Specifically, in arm A (oral rucaparib; $n=33$ ) patients discontinued treatment primarily because of objective progression or relapse (18 patients, $54.5 \%$ ), global deterioration of health status (5 patients, 15.2\%), AE (3 patients,
9.1\%), no longer willing to participate in the study (2 patients, $6.1 \%$ ), and other (5 patients, $15.2 \%$ ).

Dose-limiting toxicity and maximum tolerated dose. In arm A (oral rucaparib), no patients experienced a DLT at doses up to $360 \mathrm{mg}$ rucaparib in combination with AUC4 carboplatin. The first three patients who received $360 \mathrm{mg}$ rucaparib in combination with AUC5 carboplatin experienced dose interruptions associated with neutropenia, although these were grade $\leqslant 3$ and did not meet the protocol-specified definition of a DLT. Therefore, a decision was made to enrol an additional three patients to further evaluate the safety and tolerability of this dose combination. Dose-limiting toxicities of grade 4 thrombocytopenia and grade 4 neutropenia were observed in the first two patients treated, and thus the third additional patient was not enrolled. The rucaparib dose was deescalated to $240 \mathrm{mg}$ and three patients were treated. One patient experienced a DLT (grade 4 thrombocytopenia), and thus an additional three patients were enrolled. None of these three additional patients had a DLT. Therefore, AUC5 carboplatin and $240 \mathrm{mg}$ once daily (q.d.) oral rucaparib was declared the MTD.

Dose-limiting toxicities were also reported in one patient in arm $\mathrm{B}$ who was receiving $36 \mathrm{mg}$ rucaparib, $306 \mathrm{mg}$ paclitaxel, and $610 \mathrm{mg}$ carboplatin (grade 3 diarrhoea and grade 3 nausea) and in one patient in arm $\mathrm{C}$ who was receiving $12 \mathrm{mg}$ rucaparib, $900 \mathrm{mg}$ pemetrexed, and $135 \mathrm{mg}$ cisplatin (grade 3 fatigue, grade 4 leukopenia, and grade 4 neutropenia). Because of a decision to discontinue recruitment to the i.v. rucaparib arms during the study, no MTD was determined for arms A (i.v. rucaparib), $\mathrm{B}, \mathrm{C}$, and $\mathrm{D}$ that evaluated i.v. rucaparib in combination with chemotherapy. 
Table 2. Treatment-emergent adverse events of any grade reported in $>20 \%$ of patients in any treatment group

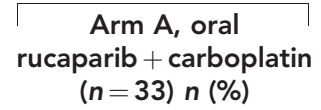

\begin{tabular}{|c|c|c|c|c|c|c|c|}
\hline Event & $\begin{array}{l}\text { Arm A, i.v. } \\
\text { rucaparib + } \\
\text { carboplatin } \\
(n=18) \\
n(\%)\end{array}$ & $\begin{array}{l}\text { Arm B, i.v. } \\
\text { rucaparib + } \\
\text { carboplatin/ } \\
\text { paclitaxel } \\
(n=13), n(\%)\end{array}$ & $\begin{array}{l}\text { Arm C, i.v. } \\
\text { rucaparib }+ \\
\text { cisplatin/ } \\
\text { pemetrexed } \\
(n=16), n(\%)\end{array}$ & $\begin{array}{l}\text { Arm D, i.v. } \\
\text { rucaparib + } \\
\text { epirubicin/ } \\
\text { cyclophosphamide } \\
(n=5), n(\%)\end{array}$ & $\begin{array}{l}\text { Any } \\
\text { grade }\end{array}$ & $\begin{array}{c}\text { Grade } \\
\geqslant 3\end{array}$ & $\begin{array}{c}\text { All patients } \\
(N=85), n(\%)\end{array}$ \\
\hline Nausea & $14(77.8)$ & $7(53.8)$ & $10(62.5)$ & $4(80.0)$ & $23(69.7)$ & $4(12.1)$ & $58(68.2)$ \\
\hline Fatigue & $14(77.8)$ & $4(30.8)$ & $14(87.5)$ & $1(20.0)$ & $20(60.6)$ & $2(6.1)$ & $53(62.4)$ \\
\hline Constipation & $10(55.6)$ & $5(38.5)$ & $9(56.3)$ & $1(20.0)$ & $17(51.5)$ & $1(3.0)$ & $42(49.4)$ \\
\hline Vomiting & $8(44.4)$ & $5(38.5)$ & $8(50.0)$ & $1(20.0)$ & $16(48.5)$ & $4(12.1)$ & $38(44.7)$ \\
\hline Anaemia & $6(33.3)$ & $2(15.4)$ & $8(50.0)$ & 0 & $18(54.5)$ & $4(12.1)$ & $34(40.0)$ \\
\hline Neutropenia & $8(44.4)$ & $7(53.8)$ & $8(50.0)$ & 0 & $11(33.3)$ & $7(21.2)$ & $34(40.0)$ \\
\hline Diarrhoea & 7 (38.9) & $5(38.5)$ & $9(56.3)$ & $1(20.0)$ & $11(33.3)$ & $1(3.0)$ & $33(38.8)$ \\
\hline Thrombocytopenia & $6(33.3)$ & $3(23.1)$ & $5(31.3)$ & 0 & $15(45.5)$ & $9(27.3)$ & $29(34.1)$ \\
\hline Decreased appetite & $5(27.8)$ & 0 & $4(25.0)$ & $2(40.0)$ & $12(36.4)$ & 0 & $23(27.1)$ \\
\hline Abdominal pain & $3(16.7)$ & $3(23.1)$ & $1(6.3)$ & 0 & $12(36.4)$ & $2(6.1)$ & 19 (22.4) \\
\hline Headache & $5(27.8)$ & $2(15.4)$ & $4(25.0)$ & $1(20.0)$ & $7(21.2)$ & 0 & 19 (22.4) \\
\hline Dyspnoea & $5(27.8)$ & $1(7.7)$ & $5(31.3)$ & $1(20.0)$ & $7(21.2)$ & $2(6.1)$ & $19(22.4)$ \\
\hline Cough & $2(11.1)$ & 0 & $6(37.5)$ & 0 & $8(24.2)$ & 0 & $16(18.8)$ \\
\hline Lethargy & $1(5.6)$ & $6(46.2)$ & $1(6.3)$ & 0 & $7(21.2)$ & 0 & $15(17.6)$ \\
\hline Back pain & $3(16.7)$ & $1(7.7)$ & $1(6.3)$ & 0 & $10(30.3)$ & $1(3.0)$ & $15(17.6)$ \\
\hline Alopecia & $2(11.1)$ & $10(76.9)$ & $2(12.5)$ & 0 & $1(3.0)$ & 0 & $15(17.6)$ \\
\hline Stomatitis & $4(22.2)$ & $6(46.2)$ & $1(6.3)$ & $1(20.0)$ & $2(6.1)$ & 0 & $14(16.5)$ \\
\hline Pyrexia & $3(16.7)$ & $1(7.7)$ & $3(18.8)$ & $2(40.0)$ & $5(15.2)$ & 0 & $14(16.5)$ \\
\hline Dyspepsia & $2(11.1)$ & $2(15.4)$ & $4(25.0)$ & 0 & $4(12.1)$ & 0 & $12(14.1)$ \\
\hline Oral candidiasis & $1(5.6)$ & $2(15.4)$ & $6(37.5)$ & $1(20.0)$ & $1(3.0)$ & 0 & $11(12.9)$ \\
\hline Arthralgia & $2(11.1)$ & $3(23.1)$ & $4(25.0)$ & 0 & $2(6.1)$ & 0 & $11(12.9)$ \\
\hline Neuropathy peripheral & 0 & $7(53.8)$ & $3(18.8)$ & 0 & 0 & 0 & $10(11.8)$ \\
\hline Insomnia & $1(5.6)$ & 0 & $5(31.3)$ & 0 & $3(9.1)$ & 0 & $9(10.6)$ \\
\hline Abdominal pain upper & $2(11.1)$ & $1(7.7)$ & 0 & $2(40.0)$ & $3(9.1)$ & $1(3.0)$ & $8(9.4)$ \\
\hline Epistaxis & $1(5.6)$ & 0 & $5(31.3)$ & 0 & 0 & 0 & $6(7.1)$ \\
\hline Tachycardia & $2(11.1)$ & 0 & $4(25.0)$ & 0 & 0 & 0 & $6(7.1)$ \\
\hline Asthenia & 0 & 0 & 0 & $4(80.0)$ & 0 & 0 & $4(4.7)$ \\
\hline Influenza-like illness & 0 & 0 & $4(25.0)$ & 0 & 0 & 0 & $4(4.7)$ \\
\hline
\end{tabular}

Adverse events. All except one patient experienced an AE during the study. Adverse events occurring in $>20 \%$ of patients in any treatment group are summarised in Table 2. Across the treatment arms, AEs were generally grade 1 or 2 in severity. The most common AEs (with $\geqslant 30 \%$ incidence in all patients) across groups were gastrointestinal events (i.e., nausea, constipation, vomiting, and diarrhoea), fatigue, and events related to myelosuppression (i.e., anaemia, neutropenia, and thrombocytopenia). Grade $\geqslant 3$ AEs were reported in 64 of 85 patients $(75.3 \%)$, the most frequent of which were neutropenia (23 patients, $27.1 \%$ ), thrombocytopenia (16 patients, $18.8 \%$ ), fatigue (11 patients, $12.9 \%)$, anaemia (10 patients, $11.8 \%)$, nausea (6 patients, $7.1 \%)$, and the following in 5 patients (5.9\%) each: vomiting, $\gamma$-glutamyltransferase increased, and dyspnoea. Myelosuppression was managed through transfusion or supportive medication when necessary; one patient (in arm C) received granulocyte colonystimulating factor in response to grade 2 neutropenia. Treatmentrelated AEs, as assessed by investigators, were reported in $94.1 \%$ of patients (Supplementary Table S1).

Across treatment arms, 22 patients (25.9\%) discontinued treatment because of AEs that included neutropenia (3 patients, 3.5\%), thrombocytopenia ( 2 patients, $2.4 \%$ ), and platinum hypersensitivity ( 2 patients, $2.4 \%)$. While on study, 6 patients $(7.1 \%)$ died of disease progression that was assessed as unrelated to study drug.
Pharmacokinetics. Rucaparib exposure increased approximately dose proportionally when given orally or intravenously (Supplementary Tables S2-S5). On study day 14, the steady-state $\mathrm{AUC}_{0-24}$ increased by an average of $61 \%$, with no change in $t_{1 / 2}$ compared with a single dose. Regardless of the administration route, the doseindependent $t_{1 / 2}$ was $\approx 17 \mathrm{~h}$ as observed in patients from arm $\mathrm{A}$ (oral rucaparib) who received $27 \mathrm{mg}$ i.v. rucaparib on day -10 and $80 \mathrm{mg}$ oral rucaparib on day -5 (Figure 2). Rucaparib demonstrated good absorption, with a dose-independent mean oral bioavailability of $36 \%$ in the fasted state. Rucaparib oral PK was not affected by coadministration of AUC3 to AUC5 carboplatin (Table 3). No apparent impact on i.v. rucaparib PK was observed with coadministration of carboplatin + paclitaxel, cisplatin + pemetrexed, or epirubicin + cyclophosphamide (Table 3 ).

Tumour response. Tumour response data were available for 77 of 85 patients. Across all cohorts, 1 patient (1.2\%) with breast cancer achieved a confirmed complete response (CR) and 9 patients (10.6\%) achieved a partial response (PR) that was confirmed in 7 patients (Table 4). Forty-three patients (50.6\%) achieved stable disease (SD). Among patients with available data, across all cohorts, the disease control rate (CR, PR, or SD for $\geqslant 12$ weeks) was $68.8 \%$. Three of 33 patients $(9.1 \%)$ receiving oral rucaparib in 


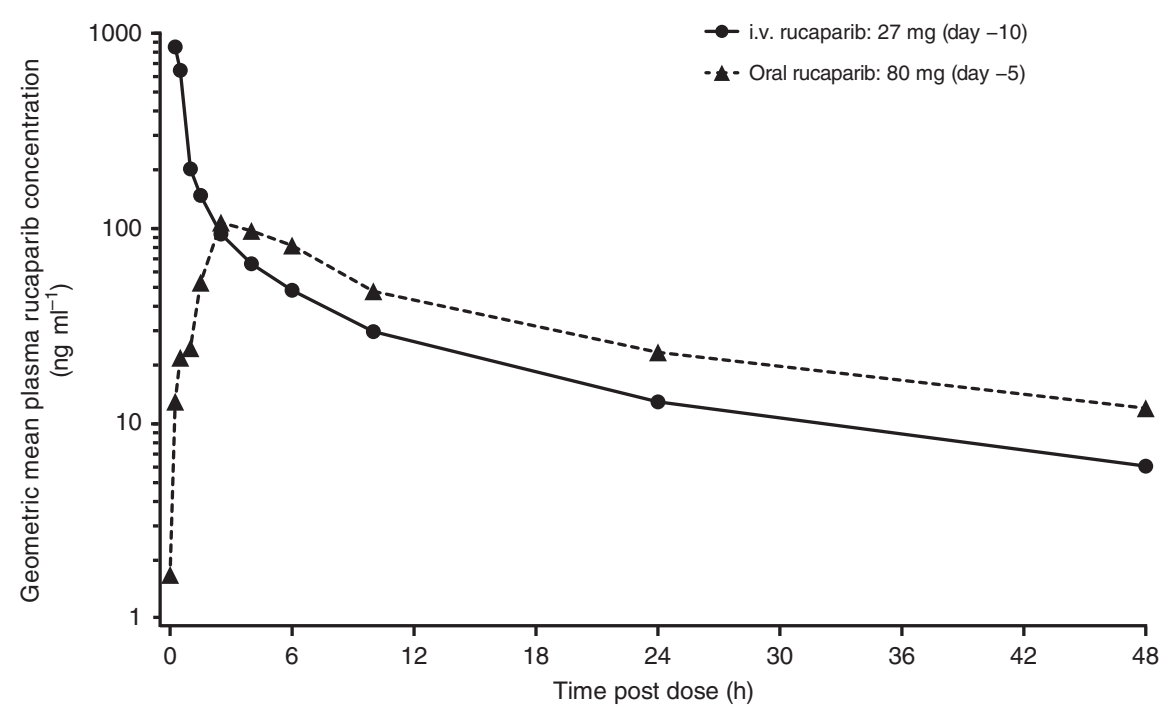

Figure 2. Plasma rucaparib concentration-time profile following i.v. or oral administration. Graph shows the geometric mean plasma concentration of rucaparib in patients in arm A (oral rucaparib) $(n=4)$ who received i.v. and oral doses on days -10 and -5 , respectively.

Table 3. Effect of carboplatin on oral rucaparib PK parameters and of chemotherapy on i.v. rucaparib PK parameters

\begin{tabular}{|c|c|c|}
\hline & \multicolumn{2}{|c|}{ Ratio of rucaparib PK parameters, ${ }^{a}$ mean (CV\%) } \\
\hline \multicolumn{3}{|l|}{ Oral rucaparib } \\
\hline AUC3 $(n=15)$ & $1.25(46)$ & $1.27(37)$ \\
\hline AUC4 $(n=3)$ & $0.928(24)$ & $1.15(51)$ \\
\hline AUC5 $(n=11)$ & $1.14(59)$ & $1.00(48)$ \\
\hline \multirow[t]{2}{*}{ Overall $(n=29)$} & $1.18(49)$ & $1.15(87)$ \\
\hline & $\mathrm{C}_{\max }$ & $A \cup C_{0-24}$ \\
\hline \multicolumn{3}{|l|}{ i.v. rucaparib } \\
\hline \multicolumn{3}{|l|}{ Chemotherapy } \\
\hline Carboplatin $(n=6)$ & $1.03(16)$ & $1.02(15)$ \\
\hline Carboplatin + paclitaxel $(n=6)$ & $0.917(16)$ & $0.86(8)$ \\
\hline Cisplatin + pemetrexed $(n=8)$ & $0.853(42)$ & $0.959(20)$ \\
\hline \multicolumn{3}{|c|}{ 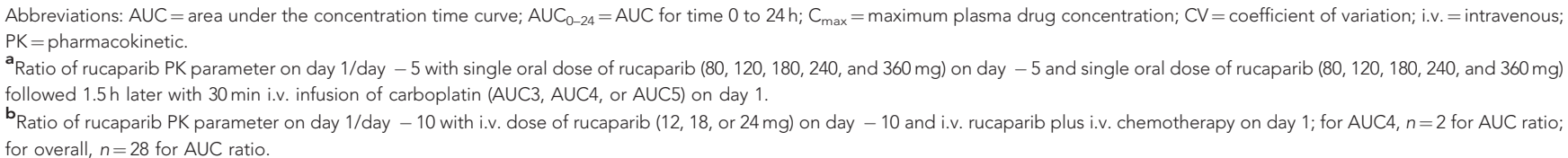 } \\
\hline
\end{tabular}

combination with carboplatin had a confirmed PR. These included a patient with ovarian/peritoneal cancer (BRCA1 mutation, BRCA2 wild type) who had a PR for 7 months, a second patient with ovarian/peritoneal cancer (BRCA1 and BRCA2 wild type) who had a PR for 5 months, and a patient with breast cancer (BRCA1 mutation, BRCA2 not tested) who had a PR for 3 months. None of these patients had received prior PARP inhibitor therapy.

\section{DISCUSSION}

This phase I study demonstrated that oral rucaparib can be safely combined with a clinically relevant dose of carboplatin in patients with an advanced solid tumour. The MTD and recommended dose for the combination is $240 \mathrm{mg}$ q.d. rucaparib on days $1-14$ with AUC5 carboplatin on day 1 in 21-day cycles.

Oral rucaparib demonstrated dose-proportional kinetics and a long $t_{1 / 2}(\approx 17 \mathrm{~h})$ with good oral bioavailability $(36 \%)$ independent of dose, all of which are desirable characteristics for an oral agent. These PK findings with oral rucaparib are consistent with results from the phase I portion of an ongoing phase I-II study evaluating single-agent oral rucaparib in patients with advanced solid tumours (Kristeleit et al, 2014). Pharmacokinetic exposure to oral rucaparib was not changed by carboplatin coadministration. When used in combination with AUC5 carboplatin, the i.v. rucaparib doses of 12,18 , and $24 \mathrm{mg}$ evaluated were approximately equivalent to oral rucaparib doses of 33,50, and $67 \mathrm{mg}$, respectively, representing $14 \%, 21 \%$, and $28 \%$ of the MTD of $240 \mathrm{mg}$ oral rucaparib.

As anticipated with the concurrent administration of chemotherapeutic agents with rucaparib, myelosuppression (anaemia, neutropenia, and thrombocytopenia) was commonly reported. Myelosuppression is a known toxicity associated with a high dose of PARP inhibitors and is also often observed with many chemotherapy regimens (Sandhu et al, 2013; Plummer et al, 2014; Kaufman et al, 2015; Shapira-Frommer et al, 2015). In our study, 
Table 4. Investigator-assessed objective tumour response

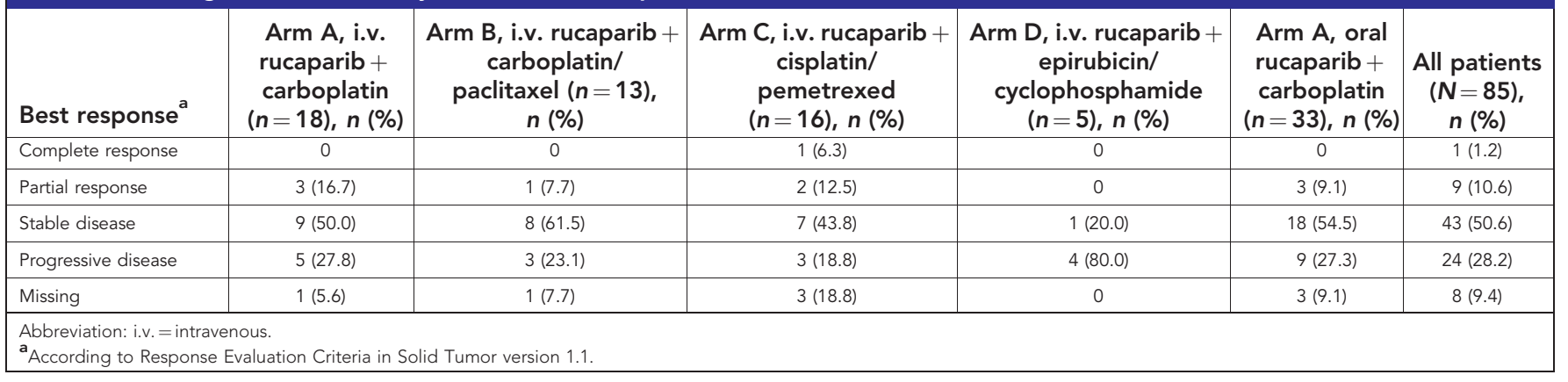

thrombocytopenia and neutropenia were DLTs and also the most common severe toxicities reported across all treatment arms. Myelosuppression was also observed in $54 \%$ of patients treated with the combination of i.v. rucaparib and temozolomide in another study (Plummer et al, 2013). The combination of the PARP inhibitor olaparib with chemotherapy, including carboplatin, has also been associated with substantial hematologic toxicity in phase I studies of patients with an advanced solid tumour (Khan et al, 2011; Rajan et al, 2012; Samol et al, 2012; Dent et al, 2013; Lee et al, 2014a).

Rucaparib exhibited clinical activity in combination with chemotherapy in this study of heavily pretreated patients with advanced malignancies. More than two-thirds of all patients in the study had stable disease or better, and this is notable because patients were not preselected for HRD (only 10 of 85 patients were known to harbour a $B R C A$ mutation). Of patients who received oral rucaparib and carboplatin, 63.6\% achieved disease control for $\geqslant 12$ weeks, and PRs were reported in 3 patients with ovarian or breast cancer, 2 of whom had a known BRCA mutation. The benefits of inhibiting PARP in BRCA-mutated ovarian or breast cancer are well documented (Fong et al, 2009; Audeh et al, 2010; Tutt et al, 2010; Kaye et al, 2012; Sandhu et al, 2013; Lee et al, 2014b). As a single agent, oral rucaparib has demonstrated activity against BRCA-mutated ovarian and breast cancer (Shapira-Frommer et al, 2015; Drew et al, 2016; Swisher et al, 2017) and is currently being evaluated in phase III studies as both maintenance and treatment therapy for patients with relapsed, high-grade ovarian cancer (ARIEL3 (NCT01968213) and ARIEL4 (NCT02855944)).

When used in combination with carboplatin, the dose of rucaparib (240 mg q.d.) is lower than the MTD of single-agent rucaparib (600 mg twice daily). The lower dose of rucaparib in the combination fits with prior studies demonstrating a synergistic effect with combinations of PARP inhibitors and DNA-damaging agents at lower doses (Calabrese et al, 2004; Donawho et al, 2007; Thomas et al, 2007; Ihnen et al, 2013). Given that platinum-based chemotherapies increase the burden of DNA damage in cells, the addition of PARP inhibition increases the cytotoxicity of these agents by preventing repair of damaged DNA. Although PARP inhibitors in the single-agent setting have demonstrated benefits in DNA-repairdeficient cancers (e.g., BRCA-mutated ovarian cancer), combinations such as rucaparib and carboplatin may be useful in a wider population, including in cancers with and without homologous repair deficiency.

In conclusion, this study demonstrated that oral rucaparib can be safely combined with a clinically relevant dose of carboplatin; however, neutropenia and thrombocytopenia were commonly observed with the rucaparib/carboplatin combination. All patients who receive rucaparib in combination with carboplatin should be monitored carefully for myelosuppression. The oral and i.v. PK profile of rucaparib was not affected by coadministration of the chemotherapeutic agents that were investigated in this study. Three heavily pretreated patients who received oral rucaparib and carboplatin had a clinical response; further work investigating this combination may be warranted.

\section{ACKNOWLEDGEMENTS}

We thank the staff of the Belfast City Hospital; Beatson West of Scotland Cancer Centre, Glasgow; Churchill Hospital, Oxford; Royal Marsden Hospital, London; Guy's Hospital, London; Institut Curie, Paris; and the Northern Centre for Cancer Care, Newcastle. Above all, we particularly thank our patients, their families, and friends for their support and participation in this trial. This study was funded by Clovis Oncology, Inc., and Cancer Research UK and the UK Department of Health funding for the UK Experimental Cancer Medicine Centre Network (to RHW, TRJE, MRM, LRM, JS, and RP). Writing and editorial assistance funded by Clovis Oncology, was provided by Tim Lohret, Nathan Yardley, and Shannon Davis of Ashfield Healthcare Communications (Middletown, CT, USA).

\section{CONFLICT OF INTEREST}

RHW has received an honorarium from Clovis Oncology for attending an advisory board relating to rucaparib. The institution of TRJE has received reimbursement of study costs for this clinical trial and an honorarium from Clovis Oncology for his participation in an advisory board for another compound. MRM, LRM, JS, $\mathrm{VD}$, and PR have no conflict of interest to declare. HG is an employee of Clovis Oncology. SJ-T was an employee of Clovis Oncology at the time of the study. SG is an employee of Clovis Oncology. RP has received honoraria for attending advisory boards relating to rucaparib, is named on a patent of use for rucaparib for which her institution will receive milestone payments, and has received research funding relating to this agent.

\section{REFERENCES}

Ashworth A (2008) A synthetic lethal therapeutic approach: poly(ADP) ribose polymerase inhibitors for the treatment of cancers deficient in DNA double-strand break repair. J Clin Oncol 26: 3785-3790.

Audeh MW, Carmichael J, Penson RT, Friedlander M, Powell B, BellMcGuinn KM, Scott C, Weitzel JN, Oaknin A, Loman N, Lu K, Schmutzler RK, Matulonis U, Wickens M, Tutt A (2010) Oral poly(ADPribose) polymerase inhibitor olaparib in patients with BRCA1 or BRCA2 mutations and recurrent ovarian cancer: a proof-of-concept trial. Lancet 376: $245-251$.

Bryant HE, Schultz N, Thomas HD, Parker KM, Flower D, Lopez E, Kyle S, Meuth M, Curtin NJ, Helleday T (2005) Specific killing of BRCA2deficient tumours with inhibitors of poly(ADP-ribose) polymerase. Nature 434: 913-917.

Calabrese CR, Almassy R, Barton S, Batey MA, Calvert AH, Canan-Koch S, Durkacz BW, Hostomsky Z, Kumpf RA, Kyle S, Li J, Maegley K, 
Newell DR, Notarianni E, Stratford IJ, Skalitzky D, Thomas HD, Wang LZ, Webber SE, Williams KJ, Curtin NJ (2004) Anticancer chemosensitization and radiosensitization by the novel poly(ADP-ribose) polymerase-1 inhibitor AG14361. J Natl Cancer Inst 96: 56-67.

Ceccaldi R, Liu JC, Amunugama R, Hajdu I, Primack B, Petalcorin MI, O'Connor KW, Konstantinopoulos PA, Elledge SJ, Boulton SJ, Yusufzai T, D'Andrea AD (2015) Homologous-recombination-deficient tumours are dependent on Poltheta-mediated repair. Nature 518: 258-262.

Clark CC, Weitzel JN, O'Connor TR (2012) Enhancement of synthetic lethality via combinations of ABT-888, a PARP inhibitor, and carboplatin in vitro and in vivo using BRCA1 and BRCA2 isogenic models. Mol Cancer Ther 11: 1948-1958.

Dent RA, Lindeman GJ, Clemons M, Wildiers H, Chan A, McCarthy NJ, Singer CF, Lowe ES, Watkins CL, Carmichael J (2013) Phase I trial of the oral PARP inhibitor olaparib in combination with paclitaxel for first- or second-line treatment of patients with metastatic triple-negative breast cancer. Breast Cancer Res 15: R88.

Donawho CK, Luo Y, Luo Y, Penning TD, Bauch JL, Bouska JJ, BontchevaDiaz VD, Cox BF, DeWeese TL, Dillehay LE, Ferguson DC, GhoreishiHaack NS, Grimm DR, Guan R, Han EK, Holley-Shanks RR, Hristov B, Idler KB, Jarvis K, Johnson EF, Kleinberg LR, Klinghofer V, Lasko LM, Liu X, Marsh KC, McGonigal TP, Meulbroek JA, Olson AM, Palma JP, Rodriguez LE, Shi Y, Stavropoulos JA, Tsurutani AC, Zhu GD, Rosenberg SH, Giranda VL, Frost DJ (2007) ABT-888, an orally active poly(ADP-ribose) polymerase inhibitor that potentiates DNA-damaging agents in preclinical tumor models. Clin Cancer Res 13: 2728-2737.

Drew Y, Ledermann J, Hall G, Rea D, Glasspool R, Highley MS, Jayson GC, Sludden J, Murray J, Jamieson D, Halford S, Acton G, Backholer Z, Mangano R, Boddy A, Curtin N, Plummer E (2016) Phase 2 multicentre trial investigating intermittent and continuous dosing schedules of the poly(ADP-ribose) polymerase inhibitor rucaparib in germline BRCA mutation carriers with advanced ovarian and breast cancer. $\mathrm{Br} J$ Cancer 114: $723-730$

Drew Y, Mulligan EA, Vong WT, Thomas HD, Kahn S, Kyle S, Mukhopadhyay A, Los G, Hostomsky Z, Plummer ER, Edmondson RJ, Curtin NJ (2011) Therapeutic potential of poly(ADP-ribose) polymerase inhibitor AG014699 in human cancers with mutated or methylated BRCA1 or BRCA2. J Natl Cancer Inst 103: 334-346.

Eisenhauer EA, Therasse P, Bogaerts J, Schwartz LH, Sargent D, Ford R, Dancey J, Arbuck S, Gwyther S, Mooney M, Rubinstein L, Shankar L, Dodd L, Kaplan R, Lacombe D, Verweij J (2009) New response evaluation criteria in solid tumours: revised RECIST guideline (version 1.1). Eur $J$ Cancer 45: 228-247.

Evers B, Drost R, Schut E, de Bruin M, van der Burg E, Derksen PWB, Holstege H, Liu X, van Drunen E, Beverloo HB, Smith GCM, Martin NMB, Lau A, O'Connor MJ, Jonkers J (2008) Selective inhibition of BRCA2-deficient mammary tumor cell growth by AZD2281 and cisplatin. Clin Cancer Res 14: 3916-3925.

Farmer H, McCabe N, Lord CJ, Tutt ANJ, Johnson DA, Richardson TB, Santarosa M, Dillon KJ, Hickson I, Knights C, Martin NMB, Jackson SP, Smith GCM, Ashworth A (2005) Targeting the DNA repair defect in BRCA mutant cells as a therapeutic strategy. Nature 434: 917-921.

Fast DM, Kelley M, Viswanathan CT, O'Shaughnessy J, King SP, Chaudhary A, Weiner R, DeStefano AJ, Tang D (2009) Workshop report and follow-up-AAPS workshop on current topics in GLP bioanalysis: assay reproducibility for incurred samples-implications of Crystal City recommendations. AAPS J 11: 238-241.

Fong PC, Boss DS, Yap TA, Tutt A, Wu P, Mergui-Roelvink M, Mortimer P, Swaisland H, Lau A, O'Connor MJ, Ashworth A, Carmichael J, Kaye SB, Schellens JHM, de Bono JS (2009) Inhibition of poly(ADP-ribose) polymerase in tumors from BRCA mutation carriers. N Engl J Med 361: 123-134.

Helleday T (2011) The underlying mechanism for the PARP and BRCA synthetic lethality: clearing up the misunderstandings. Mol Oncol 5: 387-393.

Helleday T, Lo J, van Gent DC, Engelward BP (2007) DNA double-strand break repair: from mechanistic understanding to cancer treatment. DNA Repair 6: 923-935.

Helleday T, Petermann E, Lundin C, Hodgson B, Sharma RA (2008) DNA repair pathways as targets for cancer therapy. Nat Rev Cancer 8: 193-204.

Ihnen M, zu Eulenburg C, Kolarova T, Qi JW, Manivong K, Chalukya M, Dering J, Anderson L, Ginther C, Meuter A, Winterhoff B, Jones S, Velculescu VE, Venkatesan N, Rong H-M, Dandekar S, Udar N, Jänicke F, Los G, Slamon DJ, Konecny GE (2013) Therapeutic potential of the
poly(ADP-ribose) polymerase inhibitor rucaparib for the treatment of sporadic human ovarian cancer. Mol Cancer Ther 12: 1002-1015.

Kaufman B, Shapira-Frommer R, Schmutzler RK, Audeh MW, Friedlander M, Balmaña J, Mitchell G, Fried G, Stemmer SM, Hubert A, Rosengarten O, Steiner M, Loman N, Bowen K, Fielding A, Domchek SM (2015) Olaparib monotherapy in patients with advanced cancer and a germline BRCA1/2 mutation. J Clin Oncol 33: 244-250.

Kaye SB, Lubinski J, Matulonis U, Ang JE, Gourley C, Karlan BY, Amnon A, Bell-McGuinn KM, Chen LM, Friedlander M, Safra T, Vergote I, Wickens M, Lowe ES, Carmichael J, Kaufman B (2012) Phase II, open-label, randomized, multicenter study comparing the efficacy and safety of olaparib, a poly (ADP-ribose) polymerase inhibitor, and pegylated liposomal doxorubicin in patients with BRCA1 or BRCA2 mutations and recurrent ovarian cancer. J Clin Oncol 30: 372-379.

Khan OA, Gore M, Lorigan P, Stone J, Greystoke A, Burke W, Carmichael J, Watson AJ, McGown G, Thorncroft M, Margison GP, Califano R, Larkin J, Wellman S, Middleton MR (2011) A phase I study of the safety and tolerability of olaparib (AZD2281, KU0059436) and dacarbazine in patients with advanced solid tumours. Br J Cancer 104: 750-755.

Konstantinopoulos PA, Ceccaldi R, Shapiro GI, D’Andrea AD (2015) Homologous recombination deficiency: exploiting the fundamental vulnerability of ovarian cancer. Cancer Discov 5: 1137-1154.

Kristeleit RS, Burris HA, LoRusso P, Patel MR, Asghar US, El-Khouly F, Calvert AH, Infante JR, Hilton JF, Tolaney SM, Kittaneh M, Giordano H, Borrow J, Jaw-Tsai SS, Shapiro G (2014) Phase 1/2 study of oral rucaparib: final phase 1 results. J Clin Oncol 32: 2573.

Lee JM, Hays JL, Annunziata CM, Noonan AM, Minasian L, Zujewski JA, Yu M, Gordon N, Ji J, Sissung TM, Figg WD, Azad N, Wood BJ, Doroshow J, Kohn EC (2014a) Phase I/Ib study of olaparib and carboplatin in BRCA1 or BRCA2 mutation-associated breast or ovarian cancer with biomarker analyses. J Natl Cancer Inst 106: dju089.

Lee JM, Ledermann JA, Kohn EC (2014b) PARP Inhibitors for BRCA1/2 mutation-associated and BRCA-like malignancies. Ann Oncol 25: 32-40.

Mateos-Gomez PA, Gong F, Nair N, Miller KM, Lazzerini-Denchi E, Sfeir A (2015) Mammalian polymerase [THGR] promotes alternative NHEJ and suppresses recombination. Nature 518: 254-257.

Moynahan ME, Chiu JW, Koller BH, Jasin M (1999) Brcal controls homology-directed DNA repair. Mol Cell 4: 511-518.

Moynahan ME, Pierce AJ, Jasin M (2001) BRCA2 is required for homologydirected repair of chromosomal breaks. Mol Cell 7: 263-272.

Murai J, Huang SY, Das BB, Renaud A, Zhang Y, Doroshow JH, Ji J, Takeda S, Pommier Y (2012) Trapping of PARP1 and PARP2 by clinical PARP inhibitors. Cancer Res 72: 5588-5599.

O'Connor MJ (2015) Targeting the DNA damage response in cancer. Mol Cell 60: $547-560$.

Pedersen B, Konstantinopoulos PA, Spillman MA, De S (2013) Copy neutral loss of heterozygosity is more frequent in older ovarian cancer patients. Genes Chromosomes Cancer 52: 794-801.

Plummer R, Jones C, Middleton M, Wilson R, Evans J, Olsen A, Curtin N, Boddy A, McHugh P, Newell D, Harris A, Johnson P, Steinfeldt H, Dewji R, Wang D, Robson L, Calvert H (2008) Phase I study of the poly(ADP-ribose) polymerase inhibitor, AG014699, in combination with temozolomide in patients with advanced solid tumors. Clin Cancer Res 14: 7917-7923.

Plummer R, Lorigan P, Steven N, Scott L, Middleton MR, Wilson RH, Mulligan E, Curtin N, Wang D, Dewji R, Abbattista A, Gallo J, Calvert H (2013) A phase II study of the potent PARP inhibitor, Rucaparib (PF-01367338, AG014699), with temozolomide in patients with metastatic melanoma demonstrating evidence of chemopotentiation. Cancer Chemother Pharmacol 71: 1191-1199.

Plummer R, Stephens P, Aissat-Daudigny L, Cambois A, Moachon G, Brown PD, Campone M (2014) Phase 1 dose-escalation study of the PARP inhibitor CEP-9722 as monotherapy or in combination with temozolomide in patients with solid tumors. Cancer Chemother Pharmacol 74: 257-265.

Rajan A, Carter CA, Kelly RJ, Gutierrez M, Kummar S, Szabo E, Yancey MA, Ji J, Mannargudi B, Woo S, Spencer S, Figg WD, Giaccone G (2012) A phase I combination study of olaparib with cisplatin and gemcitabine in adults with solid tumors. Clin Cancer Res 18: 2344-2351.

Samol J, Ranson M, Scott E, Macpherson E, Carmichael J, Thomas A, Cassidy J (2012) Safety and tolerability of the poly(ADP-ribose) polymerase (PARP) inhibitor, olaparib (AZD2281) in combination with topotecan for the treatment of patients with advanced solid tumors: a phase I study. Invest New Drugs 30: 1493-1500. 
Sandhu SK, Schelman WR, Wilding G, Moreno V, Baird RD, Miranda S, Hylands L, Riisnaes R, Forster M, Omlin A, Kreischer N, Thway K, Gevensleben H, Sun L, Loughney J, Chatterjee M, Toniatti C, Carpenter CL, Iannone R, Kaye SB, de Bono JS, Wenham RM (2013) The poly(ADP-ribose) polymerase inhibitor niraparib (MK4827) in BRCA mutation carriers and patients with sporadic cancer: a phase 1 doseescalation trial. Lancet Oncol 14: 882-892.

Schreiber V, Dantzer F, Ame JC, de Murcia G (2006) Poly(ADP-ribose): novel functions for an old molecule. Nat Rev Mol Cell Biol 7: 517-528.

Shapira-Frommer R, Oza AM, Domchek SM, Balmana J, Patel MR Chen L-M, Drew Y, Burris HA, Korach J, Flynn M, Bowering VL, Morgan MA, Watkins SP, Simpson D, Goble S, Maloney L, Kristeleit RS (2015) A phase 2 open-label, multicenter study of single-agent rucaparib in the treatment of patients with relapsed ovarian cancer and a deleterious BRCA mutation. J Clin Oncol 33: 5513.

Swisher EM, Lin KK, Oza AM, Scott CL, Giordano H, Sun J, Konecny GE, Coleman RL, Tinker AV, O'Malley DM, Kristeleit RS, Ma L,

Bell-McGuinn KM, Brenton JD, Cragun JM, Oaknin A, Ray-Coquard I, Harrell MI, Mann E, Kaufmann SH, Floquet A, Leary A, Harding TC, Goble S, Maloney L, Isaacson J, Allen AR, Rolfe L, Yelensky R, Raponi M, McNeish IA (2017) Rucaparib in relapsed, platinum-sensitive high-grade ovarian carcinoma (ARIEL2 Part 1): an international, multicentre, openlabel, phase 2 trial. Lancet Oncol 18: 75-87.

Thomas HD, Calabrese CR, Batey MA, Canan S, Hostomsky Z, Kyle S, Maegley KA, Newell DR, Skalitzky D, Wang LZ, Webber SE, Curtin NJ
(2007) Preclinical selection of a novel poly(ADP-ribose) polymerase inhibitor for clinical trial. Mol Cancer Ther 6: 945-956.

Tutt A, Robson M, Garber JE, Domchek SM, Audeh MW, Weitzel JN, Friedlander M, Arun B, Loman N, Schmutzler RK, Wardley A, Mitchell G, Earl H, Wickens M, Carmichael J (2010) Oral poly(ADP-ribose) polymerase inhibitor olaparib in patients with BRCA1 or BRCA2 mutations and advanced breast cancer: a proof-of-concept trial. Lancet 376: 235-244.

US Food and Drug Administration (2001) Bioanalytical Method Validation (May 2001). Available from http://www.fda.gov/Drugs/ GuidanceComplianceRegulatoryInformation/Guidances/ucm064964.htm.

Venkitaraman AR (2002) Cancer susceptibility and the functions of BRCA1 and BRCA2. Cell 108: 171-182.

Viswanathan CT, Bansal S, Booth B, DeStefano AJ, Rose MJ, Sailstad J, Shah VP, Skelly JP, Swann PG, Weiner R (2007) Workshop/conference report-quantitative bioanalytical methods validation and implementation: best practices for chromatographic and ligand binding assays. AAPS J 9: E30-E42.

(c) (i) This work is licensed under the Creative Commons (c) Attribution 4.0 International License. To view a copy of this license, visit http://creativecommons.org/licenses/by/4.0/

(C) The Author(s) named above 2017

Supplementary Information accompanies this paper on British Journal of Cancer website (http://www.nature.com/bjc) 